\title{
Divergência nutricional de cascas de vagens de genótipos de feijão-fava para alimentação de ruminantes
}

\section{Nutritional divergence of peels pods of lima bean genotypes for ruminants feeding}

\author{
SILVA, Raimundo Nonato Pereira da ${ }^{1 *}$; ALVES, Arnaud Azevêdo ${ }^{1}$; CAMPELO, José \\ Elivalto Guimarães ${ }^{1}$; COSTA, Márcio da Silva ${ }^{2}$; MOREIRA, Antônia Leidiana ; \\ GARCEZ, Bruno Spíndola ; PARENTE, Henrique Nunes ${ }^{4}$; AZEVÊDO, Danielle Maria \\ Machado Ribeiro ${ }^{3}$
}

\footnotetext{
${ }^{1}$ Universidade Federal do Piauí, Centro de Ciências Agrárias, Programa de Pós-Graduação em Ciência Animal, Teresina, Piauí, Brasil.

${ }^{2}$ Universidade Federal do Piauí, Campus Cinobelina Elvas, Bom Jesus, Piauí, Brasil.

${ }^{3}$ Empresa Brasileira de Pesquisa Agropecuária,Embrapa Meio-Norte, Teresina, Piauí, Brasil.

${ }^{4}$ Universidade Federal do Maranhão, Centro de Ciências Agrárias e Ambientais, Departamento de Zootecnia, Chapadinha, Maranhão, Brasil.

*Endereço para correspondência: nonatopereirars@hotmail.com
}

\section{RESUMO}

Objetivou-se avaliar a divergência nutricional de cascas de vagens de 25 genótipos de feijãofava para alimentação de ruminantes, considerando-se a composição química, características de fermentação e cinética de degradação in situ no rúmen. Os constituintes químicos foram considerados variáveis discriminatórias em uma primeira análise, enquanto os parâmetros de cinética de degradação ruminal e a degradação efetiva (DE $2 \% \mathrm{~h}^{-1}$ ) da matéria seca foram considerados na segunda análise. Utilizou-se o método de otimização de Tocher, adotando-se a matriz de "distâncias euclidiana" média dos caracteres para avaliar a dissimilaridade entre os genótipos. Constatou-se a formação de sete grupos heterogêneos, destacando-se a fibra em detergente ácido e proteína bruta como as variáveis mais impactantes para agrupamento na primeira análise, contribuindo com 41,7 e $29,3 \%$, respectivamente, enquanto, na segunda análise, a fração solúvel (fração a) e a taxa de degradação da fração b participaram em 38,7 e $28,0 \%$ respectivamente. Os constituintes químicos PB e FDA e os parâmetros de cinética de degradação ruminal fração solúvel (fração a), taxa de degradação (c) e fração potencialmente degradável (fração b) da MS, mostram-se eficientes para conhecimento da divergência nutricional de cascas de vagens de genótipos de feijão-fava, com base em análise multivariada. Considerando-se os parâmetros adotados para a formação de agrupamentos pelo método de Tocher, o genótipo de feijão-fava 123 apresenta boa degradação efetiva e taxa de degradação compatível com a de forragens tropicais além de melhor valor nutritivo e potencial forrageiro que a casca dos demais genótipos de feijão-fava.

Palavras-chave: análise de agrupamento, Phaseolus lunatus, subproduto

\section{SUMMARY}

This research aimed to evaluate the nutritional divergence of twenty-five genotypes of peel pods of lima bean for ruminant feeding, based on chemical composition as well as fermentation and in situ degradation kinetic characteristics. The chemical constituents were considered discriminatory variables in the first analysis, while the parameters of rumen degradation kinetics and effective degradability $\left(E D 2 \% \mathrm{~h}^{-1}\right)$ of dry matter were considered in the second analysis. Was adopted the cluster analysis according to the Tocher optimization approach, considering the average Euclidian distance matrix of characters to evaluate the dissimilarity among the genotypes. It was 
verified the formation of seven heterogeneous groups, highlighting the acid detergent fiber (ADF) and crude protein (CP) as most impactful variables for grouping in the first analysis, contributing with 41.7 and $29.3 \%$, respectively, while in the second analysis, the soluble fraction degradation rate accounted for 38.7 and $28.0 \%$, respectively. The chemical constituents $\mathrm{CP}$ and $\mathrm{ADF}$ and the kinetic parameters of ruminal degradation soluble fraction (fraction $a$ ), degradation rate $(c)$ and potentially degradable fraction (fraction $b$ ) of the DM, are efficient to identify the nutritional divergence of pod shells lima bean genotypes based on multivariate analysis. Considering the parameters adopted to form a pool by Tocher's method, the lima bean genotype 123, present efficient effective degradation and degradation rate compatible with the tropical forage, and better nutritive value and forage potential than pod shells of the other lima bean genotypes.

Keywords: byproduct, cluster analysis, Phaseolus lunatus

\section{INTRODUÇÃO}

Os restolhos de culturas apresentam grande importância quando da busca de alternativas para diminuir o déficit nutricional de ruminantes no período seco do ano. Assim, volumosos como palhadas de culturas anuais de inverno e verão, fenos de baixa qualidade, silagens de capins passados, resíduos da colheita de sementes de plantas forrageiras e do beneficiamento de grãos têm sido utilizados como alternativas importantes nesse período (AZEVÊDO et al., 2011).

O feijão-fava (Phaseolus lunatus L.) consiste em uma das quatro espécies do gênero Phaseolus exploradas comercialmente (OLIVEIRA et al., 2011), considerada a segunda espécie mais importante economicamente, superada apenas pelo feijão-comum. $\mathrm{Na}$ região nordeste do Brasil, o grão desta leguminosa representa importante produto da agricultura familiar, remanescendo, como subproduto, a casca das vagens, que são armazenadas para utilização na alimentação de ruminantes no período seco do ano, se verificando bom consumo pelos animais além da facilidade de conservação.

Quando um conjunto de variáveis apresenta, qualitativamente, aspectos diferentes, não existindo correlação entre eles, a análise de variância univariada é o procedimento mais adotado. Porém, na caracterização de genótipos de forrageiras, as variáveis geralmente avaliadas são correlacionadas entre si, uma vez serem medidas em grupos com identidade comum, além de expressas em diferentes escalas ou unidades de medida, por isso, deve-se pressupor multinormalidade para análise multivariada da variância (RODRIGUES et al., 2012).

$\mathrm{Na}$ avaliação da diversidade nutricional de volumosos, vários métodos podem ser adotados, sendo a análise de agrupamento, um método de análise multivariada que envolve, simultaneamente, diversas características discriminatórias, o mais adotado na avaliação de forrageiras. Porém, é indispensável recorrer a critérios para determinar, de forma eficiente, as variáveis com características mais importantes para a discriminação da qualidade da forragem. O método de otimização de Tocher (RAO, 1952) vem sendo amplamente adotado no estudo da divergência genética em várias culturas, principalmente, na perspectiva do melhoramento (MENEZES et al., 2012; RIBEIRO et al., 2012, SOUZA et al., 2013).

Objetivou-se, com esta pesquisa, avaliar a composição química e características fermentativas ruminais das cascas de vagens de 25 genótipos de feijão-fava, como parâmetros de divergência nutricional para alimentação de ruminantes. 
Rev. Bras. Saúde Prod. Anim., Salvador, v.16, n.3, p.571-581 jul./set.., 2015 http://www.rbspa.ufba.br

\section{MATERIAL E MÉTODOS}

A pesquisa foi realizada no Departamento de Zootecnia do Centro de Ciências Agrárias (CCA) da Universidade Federal do Piauí (UFPI), em Teresina, PI. Foram avaliadas cascas de vagens de 25 genótipos de feijãofava do Banco de Germoplasma do Departamento de Fitotecnia do CCA/UFPI.

As amostras das cascas foram moídas em moinho tipo Willey, com peneira de malha com crivos de diâmetro $2 \mathrm{~mm}$, e determinou-se os teores de matéria seca (MS) e, com base na MS, a proteína bruta (PB), matéria orgânica (MO), segundo AOAC (2012). A fibra em detergente neutro (FDN) e fibra em detergente ácido (FDA) foram analisadas pelo método de Van Soest et al. (1991) (Tabela 1).

Para determinação da degradabilidade in situ da MS, foram utilizados três bovinos adultos, castrados, mestiços Girolando, com peso vivo $500 \mathrm{~kg}$, providos de cânula ruminal. As incubações in situ no rúmen foram realizadas utilizando-se sacos de náilon com dimensões $12 \times 8 \mathrm{~cm}$ e porosidade $50 \mu \mathrm{m}$, contendo, aproximadamente, $4 \mathrm{~g}$, de acordo com relação de $42 \mathrm{mg} / \mathrm{cm}^{2}$ adotada por Campos et al. (2011). Os parâmetros de degradação foram determinados a partir de dados obtidos após incubação das amostras no rúmen por 6,24 e $72 \mathrm{~h}$.

Após desincubação, os sacos foram, imediatamente, imersos em água com gelo para cessar o processo de fermentação e, em seguida, foram lavados em máquina de lavar, até a água se mostrar límpida. Para determinação da fração solúvel (tempo 0h), os sacos contendo as amostras não foram incubados no rúmen, porém imersos em água em banho-maria a $39^{\circ} \mathrm{C}$ por $1 \mathrm{~h}$.
Posteriormente, todos os sacos foram pré-secos em estufa com circulação forçada de ar a $65^{\circ} \mathrm{C}$ por $72 \mathrm{~h}$ (AOAC, 2012), para determinação da MS não degradada.

Os parâmetros de degradação da MS, fração solúvel (a), fração potencialmente degradável (b), taxa de degradação (c), degradação potencial (DP) e degradação efetiva (DE) para a taxa de passagem $\mathrm{k}=$ $2 \% \mathrm{~h}^{-1}$ (AFRC, 1993), foram obtidos a partir do modelo assintótico de primeira ordem reparametrizado por Ørskov \& McDonald (1979): $\mathrm{Y}_{\mathrm{t}}=\mathrm{a}+\mathrm{b}\left(1-\mathrm{e}^{-\mathrm{ct}}\right)$, em que: $Y_{t}=$ fração degradada no tempo $\mathrm{t} ; \mathrm{a}=$ fração solúvel; $\mathrm{b}=$ fração insolúvel potencialmente degradável; $\mathrm{c}=$ taxa de degradação da fração $\mathrm{b} ; \mathrm{t}=$ variável independente tempo. A fração efetivamente degradada da MS foi determinada pelo modelo proposto por Ørskov \& McDonald (1979): DE $=\mathrm{a}+$ $\mathrm{b} \times \mathrm{c} /(\mathrm{c}+\mathrm{k})$, em que $\mathrm{k}=2 \% \mathrm{~h}^{-1}$ é a taxa de passagem aproximada para alimentos fibrosos pelo rúmen (AFRC, 1993).

As médias dos constituintes químicos (Tabela 1) foram utilizadas como características discriminatórias da diversidade nutricional das cascas das vagens dos genótipos de feijão-fava. Este procedimento também foi adotado em uma segunda análise, utilizando-se os parâmetros de cinética de degradação ruminal e de degradação efetiva da MS (DE, $\left.\quad 2 \% \mathrm{~h}^{-1}\right), \quad$ considerando esse parâmetro como discriminativo para genótipos com maiores distâncias em relação à média.

Para avaliar a dissimilaridade entre os genótipos e definir os mais representativos da divergência, foi adotado o método de otimização de Tocher como critério de agrupamento, considerando a matriz de "distâncias euclidiana" média dos quatro caracteres que foram mantidos após a análise de componentes principais, nos dois conjuntos de dados, separadamente. As 
Rev. Bras. Saúde Prod. Anim., Salvador, v.16, n.3, p.571-581 jul./set.., 2015 http://www.rbspa.ufba.br ISSN 15199940

análises multivariadas foram realizadas utilizando-se o software sistema de análises estatísticas e genéticas - SAEG (UFV, 2000).

\section{RESULTADOS E DISCUSSÃO}

As médias dos constituintes químicos MS, MO, PB, FDN e FDA, utilizadas como características discriminatórias da diversidade nutricional das cascas das vagens dos genótipos de feijão-fava estão apresentadas na Tabela 1.
A análise da composição química indicou o teor de MS como a variável com menor contribuição $(6,6 \%)$ para a formação dos agrupamentos genéticos (Tabela 2). Esse comportamento parece ser reflexo da maior estabilidade desta variável com relação à variação entre genótipos, dificultando sua contribuição na avaliação de divergências nutricionais entre os mesmo. Os teores de matéria seca dependem da variação quantitativa dos demais nutrientes químicos, o que torna essa fração diretamente relacionada com o aumento nos teores de parede celular e proteína presente na planta.

Tabela 1. Teores de matéria seca (MS), matéria orgânica (MO), proteína bruta (PB), fibra em detergente neutro (FDN) e fibra em detergente ácido (FDA) da casca de genótipos de feijão-fava

\begin{tabular}{|c|c|c|c|c|c|}
\hline Genótipos & MS (\%) & MO (\%) & PB (\%) & FDN (\%) & FDA $(\%)$ \\
\hline Boca-de-moça $^{1}$ & 86,5 & 96,8 & 5,0 & 75,0 & 44,7 \\
\hline 35 & 86,5 & 95,1 & 5,4 & 74,5 & 52,6 \\
\hline 121 & 86,7 & 96,0 & 5,2 & 77,6 & 48,6 \\
\hline 123 & 86,7 & 96,3 & 8,5 & 73,3 & 48,9 \\
\hline 177 & 86,5 & 96,1 & 5,5 & 72,1 & 47,9 \\
\hline 220 & 86,6 & 96,4 & 4,8 & 76,5 & 52,5 \\
\hline 222 & 86,5 & 95,0 & 4,7 & 77,2 & 52,8 \\
\hline 228 & 87,0 & 95,1 & 5,9 & 75,1 & 51,5 \\
\hline 230 & 86,6 & 96,1 & 7,1 & 76,1 & 53,4 \\
\hline 243 & 86,5 & 96,1 & 7,2 & 70,5 & 51,2 \\
\hline 251 & 86,8 & 96,3 & 5,6 & 76,5 & 54,4 \\
\hline 274 & 86,6 & 95,6 & 5,7 & 79,5 & 57,2 \\
\hline 275 & 86,8 & 96,3 & 5,6 & 79,2 & 50,4 \\
\hline 276 & 86,4 & 97,0 & 6,8 & 78,2 & 52,1 \\
\hline 278 & 85,4 & 96,9 & 4,7 & 74,4 & 51,3 \\
\hline 463 & 87,1 & 96,4 & 5,7 & 76,1 & 51,6 \\
\hline 465 & 86,7 & 96,3 & 5,9 & 78,7 & 52,6 \\
\hline 468 & 86,5 & 96,3 & 5,7 & 76,5 & 53,4 \\
\hline 470 & 86,4 & 97,2 & 6,1 & 76,4 & 44,1 \\
\hline 483 & 86,3 & 96,8 & 5,7 & 81,0 & 56,0 \\
\hline 494 & 85,9 & 96,1 & 5,2 & 70,5 & 44,7 \\
\hline 500 & 86,7 & 96,0 & 5,5 & 77,5 & 51,6 \\
\hline 515 & 86,6 & 96,5 & 5,1 & 76,7 & 51,5 \\
\hline 579 & 86,3 & 96,1 & 5,3 & 74,9 & 50,9 \\
\hline 582 & 87,2 & 95,5 & 5,5 & 79,3 & 55,1 \\
\hline Média & 86,5 & 96,2 & 5,7 & 76,1 & 51,4 \\
\hline $\mathrm{EPM}^{2}$ & 0,4 & 0,6 & 0,9 & 2,7 & 3,5 \\
\hline
\end{tabular}

${ }^{1} 49$ variedades crioulas; ${ }^{2}$ erro padrão da média. 
Rev. Bras. Saúde Prod. Anim., Salvador, v.16, n.3, p.571-581 jul./set.., 2015 http://www.rbspa.ufba.br ISSN 15199940

Tabela 2. Contribuição dos constituintes químicos de valor nutritivo de cascas de genótipos de feijão-fava para a formação dos agrupamentos genéticos

\begin{tabular}{lcc}
\hline \multirow{2}{*}{ Variáveis } & \multicolumn{2}{c}{ Contribuição das variáveis (\%) } \\
\cline { 2 - 3 } & Agrupamento 1 & Agrupamento 2 \\
\hline MS (\%) & 6,6 & - \\
MO (\%MS) & 11,7 & 13,0 \\
FDN (\%MS) & 14,7 & 16,0 \\
PB (\%MS) & 27,7 & 29,3 \\
FDA (\%MS) & 39,3 & 41,7 \\
\hline
\end{tabular}

Quando do estabelecimento do limite mínimo de $10 \%$ para contribuição de cada variável, de acordo com o método de Tocher, a MS foi descartada da análise, visando obtenção do agrupamento 2. A FDA, seguida pela $\mathrm{PB}$, foram as variáveis que mais contribuíram para a divergência entre os grupos genéticos, tendo a MO e a FDN apresentado pouca relevância para a formação dos mesmos. Quanto aos constituintes fibrosos, Azevêdo et al. (2003) afirmam que, embora a técnica de componentes principais indique a variável FDN como de pouca importância na avaliação da divergência nutricional, esta variável não deve ser descartada, pois a mesma contém a hemicelulose, importante fração degradável da parede celular.

$\mathrm{O}$ teor de FDN apresenta estreita relação com o consumo das forragens e, consequentemente, com o desempenho dos animais. $\mathrm{O}$ valor médio obtido para casca de genótipos de vagem de feijãofava $(76,1 \%)$ é compatível com forrageiras tropicais (CARVALHO et al., 2006; OLIVEIRA et al., 2014), denotando possibilidade de uso em dietas de ruminantes, com cuidados quanto à disponibilidade de nitrogênio, devido ao baixo teor de PB (5,7\%).

A adoção do método de agrupamento multivariado de Tocher aos dados de composição química possibilitou $\mathrm{o}$ agrupamento das cascas de vagens dos 25 genótipos de feijão-fava em sete grupos (Tabela 3), indicando divergência genética nutricional do subproduto casca de vagens dos genótipos do feijão-fava.

O grupo I ficou composto por 16 genótipos, representando $64,0 \%$ do total, seguido pelos grupos II, III e IV, com dois genótipos por grupo e V, VI e VII, com apenas um genótipo. A limitada composição quantitativa de genótipos nos grupos II a VII decorre da influência dos genótipos distribuídos nos demais grupos, aumentando a exigência média da distância. Esta situação é característica do modelo adotado para a formação dos grupos e indica que genótipos isolados refletem grande dissimilaridade, principalmente quando se adota o método de otimização de Tocher. Quanto maior a formação de grupos, maior a identificação de divergência genética quanto às variáveis envolvidas no agrupamento (VASCONCELOS et al., 2007).

A maior representatividade das frações fibrosas das cascas de vagens dos genótipos de feijão-fava foi verificada no grupo I, com teores de FDN e FDA, $76,65 \pm 2,20 \%$ e $51,64 \pm 2,95 \%$. Os teores desses constituintes da casca de feijão podem ser considerados elevados, no entanto são consideradas entidades nutricionais e representam um conjunto de constituintes fibrosos, os quais podem interferir no consumo e degradação total da matéria seca, com impacto na disponibilidade de energia aos ruminantes. 
Rev. Bras. Saúde Prod. Anim., Salvador, v.16, n.3, p.571-581 jul./set.., 2015 http://www.rbspa.ufba.br ISSN 15199940

Tabela 3. Agrupamento das cascas de 25 acessos de feijão-fava disponíveis no banco de germoplasma da UFPI, pelo método de Tocher por distância euclidiana média intragrupo e média dos constituintes químicos de cada grupo

\begin{tabular}{|c|c|c|c|c|c|c|c|}
\hline \multirow{2}{*}{ Variáveis } & \multicolumn{7}{|c|}{ Grupos } \\
\hline & I & II & III & IV & V & VI & VII \\
\hline Genótipos & $\begin{array}{c}121,177, \\
220,228, \\
251,275, \\
278,463, \\
465,468, \\
483,500, \\
515,579, \\
582, \text { Boca } \\
\text { de moça }\end{array}$ & 276,470 & 35,222 & 123,243 & 274 & 230 & 494 \\
\hline $\begin{array}{l}\text { Distância } \\
\text { euclidiana } \\
\text { intragrupo }\end{array}$ & 1,13 & 0,46 & 0,87 & 1,07 & - & - & - \\
\hline Médias & & & & & & & \\
\hline MO (\%MS) & 82,84 & 83,44 & 81,55 & 82,78 & 82,17 & 82,73 & 81,99 \\
\hline PB $(\% \mathrm{MS})$ & 5,41 & 6,45 & 5,05 & 7,89 & 5,65 & 7,11 & 5,16 \\
\hline FDN (\%MS) & 76,65 & 76,57 & 75,84 & 71,88 & 79,51 & 76,07 & 70,47 \\
\hline FDA (\%MS) & 51,64 & 44,61 & 50,84 & 50,05 & 57,38 & 53,34 & 42,89 \\
\hline
\end{tabular}

As características da parede celular de forragens em estádio vegetativo difere das características de subprodutos fibrosos, o que justifica o maior impacto da FDA na formação de agrupamentos nesta pesquisa, como destacado por Ferreira et al. (2012), atribuindo maior poder de discriminação em métodos de grupamento e distinção de genótipo às variáveis de composição química $\mathrm{PB}$ e FDA.

$\mathrm{O}$ teor de $\mathrm{PB}$ dos genótipos do grupo I foi $5,41 \pm 0,6 \%$. Considerando-se os teores de FDN e PB, as cascas das vagens da maioria dos genótipos de feijão-fava (grupo I) apresentam composição química comparável a volumosos disponíveis nos trópicos, inclusive fenos de gramíneas. A disponibilidade de nitrogênio é um dos principais limitantes à degradação ruminal, sendo esse composto utilizado para síntese de proteína microbiana e consequente crescimento da microbiota, com melhor aproveitamento das frações do alimento.

A contribuição dos parâmetros de degradação in situ, degradação potencial (DP) e degradação efetiva (DE) da MS a $2 \% \mathrm{~h}^{-1}$ para a formação dos agrupamentos genéticos das cascas das vagens de feijão fava, está apresentada na Tabela 4.

$\mathrm{A}$ análise de divergência indicou a DP como a variável com menor contribuição $(7,67 \%)$ para a formação dos agrupamentos, sendo descartada quando do estabelecimento do limite mínimo de $10 \%$ para contribuição de cada variável, de acordo com o método de Tocher, visando obtenção do agrupamento 2. A fração solúvel (a) da MS, seguida da taxa de degradação (c) e da fração potencialmente degradável (b) foram as variáveis de cinética de degradação ruminal que mais contribuíram para a formação dos sete grupos genéticos (Tabela 4). 
Rev. Bras. Saúde Prod. Anim., Salvador, v.16, n.3, p.571-581 jul./set.., 2015 http://www.rbspa.ufba.br ISSN 15199940

Tabela 4. Contribuição dos parâmetros de degradação in situ da MS e degradação potencial (DP) e efetiva da matéria seca (DE 2\%h-1) de cascas de vagens de genótipos de feijão-fava para formação dos agrupamentos genéticos

\begin{tabular}{lcc}
\hline \multirow{2}{*}{ Variáveis } & \multicolumn{2}{c}{ Contribuição das variáveis (\%) } \\
\cline { 2 - 3 } & Agrupamento 1 & Agrupamento 2 \\
\hline Fração a (\%) & 38,0 & 38,7 \\
Fração b (\%) & 16,3 & 19,3 \\
Taxa de degradação $\left(\% \mathrm{~h}^{-1}\right)$ & 28,0 & 28,0 \\
DP $(\%)$ & 7,67 & - \\
DE 2\% & 10,0 & 14,0 \\
\hline
\end{tabular}

A importância da taxa de degradação da MS de alimentos volumosos, representada preponderantemente pela taxa de degradação de carboidratos totais, para a discriminação de grupos, também foi evidenciada por Freitas et al. (2006) para clones de cana-de-açúcar pela técnica in vitro de produção de gases, indicando consistência da adoção das técnicas in situ e de produção de gases na geração de dados para caracterização da divergência de genótipos quanto ao valor nutritivo para ruminantes. Além disso, o elevado poder discriminatório da taxa de degradação (c) da MS para formação dos grupos indica que os genótipos podem apresentar valores de DE da MS semelhantes, porém distribuídos em mais de um grupo, diferenciados, principalmente, pela velocidade de degradação da fração potencialmente degradável (b) da MS e pela própria fração potencialmente degradável (b) (MARTINS et al., 1999).

Também adotando a técnica de produção de gases, Ferreira et al. (2012) identificou comportamento diferenciado das taxas de degradação de carboidratos fibrosos e não fibrosos na formação de agrupamentos, identificando-se ser a taxa de degradação de carboidratos de rápida degradação a de maior contribuição para formação de agrupamentos de genótipos de amendoim forrageiro. Este resultado indica consistência para a adoção da fração solúvel (a) da MS, a partir do modelo de Ørskov \& McDonald (1979), como uma variável para agrupamento de genótipos de feijão-fava, por esta contemplar parte dos carboidratos não fibrosos e representar cerca de $20 \%$ da MS deste subproduto.

Quando da formação dos grupos, destacam-se os grupos I e II, compostos, respectivamente, por 36,0 e $24,0 \%$ dos genótipos, seguidos pelo grupo III, com quatro genótipos (Tabela 5). Considerando que o agrupamento permite definir variáveis mais importantes para identificação de genótipos com maior potencial forrageiro, as cascas das vagens do genótipo de feijão-fava 123 se destacam por apresentar elevada fração $b$ $(66,34 \%)$ e $60,3 \%$ desta ser degradada efetivamente (DE) a $2 \% \mathrm{~h}^{-1}$, além de apresentar taxa de degradação $2,61 \% \mathrm{~h}^{-1}$, compatível com a de volumosos tropicais, como capim-andropógon $\quad(2,81 \%)$ (SILVA et al., 2014), milheto (2,24\%) (CAVALCANTI et al., 2012) e capim Tanzânia (2,67\%) (SIMILI et al, 2014), indicando melhor potencial forrageiro que o subproduto dos demais genótipos de feijão-fava.

Os grupos I e II apresentam genótipos muito similares e representam $60,0 \%$ dos genótipos de feijão-fava avaliados. Considerando-se a elevada representatividade dos genótipos desta leguminosa nestes dois grupos, bem como a similaridade dos parâmetros de 
Rev. Bras. Saúde Prod. Anim., Salvador, v.16, n.3, p.571-581 jul./set.., 2015 http://www.rbspa.ufba.br ISSN 15199940

degradação, tanto intra quanto intergrupos, é possível considerar a média das variáveis de degradação ruminal da MS das cascas dos mesmos como representativa para o feijão-fava. Assim, têm-se as médias para fração a 20,71 $\pm 0,97$, fração b $53,25 \pm 3,57$, taxa de degradação $\quad 3,84 \pm 0,74 \% \mathrm{~h}^{-1}, \quad \mathrm{DP}$
$69,45 \pm 2,69 \%$ e DE $2 \% \mathrm{~h}^{-1} 55,25 \pm 2,14 \%$. A taxa de degradação da MS para estes 15 genótipos indica eficiente fermentação destes substratos no ambiente ruminal em função do tempo, com impacto positivo na disponibilidade de energia a partir dos produtos da degradação no rúmen.

Tabela 5. Agrupamento de cascas de genótipos de feijão-fava pelo método de Tocher, obtido com distância euclidiana média entre 25 acessos disponíveis no banco de germoplasma da UFPI e média dos parâmetros de degradação in situ e de degradação efetiva (DE 2\%h-1) da matéria seca

\begin{tabular}{lccccccc}
\hline \multirow{2}{*}{ Variáveis } & \multicolumn{7}{c}{ Grupos } \\
\cline { 2 - 8 } & \multicolumn{1}{c}{ I } & II & III & IV & V & VI & VII \\
\hline & 177 & & & & & & \\
& 222 & 121 & & & & & \\
& 251 & 230 & 220 & & & & \\
Genótipos & 274 & 275 & 470 & 228 & 276, & 123 & 243 \\
& 465 & 278 & 494 & 483 & 515 & & \\
& 468 & 463 Boca de & 500 & & & & \\
& 482 & moça & & & & & \\
Distância euclidiana & 579 & & & & & & \\
intragrupo & 0,95 & 0,90 & 0,89 & 0,73 & 0,82 & - & - \\
\hline Médias & & & & & & & \\
\hline Fração $a$ (\%) & 21,18 & 19,79 & 20,22 & 22,43 & 19,93 & 22,51 & 23,40 \\
Fração $b$ (\%) & 53,74 & 53,01 & 69,92 & 43,25 & 50,21 & 66,34 & 64,46 \\
Taxa de degradação $\left(\% \mathrm{~h}^{-1}\right)$ & 3,47 & 4,42 & 1,96 & 4,05 & 3,26 & 2,61 & 1,91 \\
DE $2 \% \mathrm{~h}^{-1}$ & 54,81 & 56,09 & 54,58 & 51,29 & 50,54 & 60,07 & 54,89 \\
\hline
\end{tabular}

Ao comparar a gramíneas tropicais, a média para DE a $2 \% \mathrm{~h}^{-1}$ da MS das cascas de vagens de genótipos de feijãofava apresenta-se equivalente às obtidas para essas forragens (VELÁSQUEZ et al., 2009) e reforça o potencial da utilização desse subproduto para inclusão em dietas para ruminantes. $\mathrm{O}$ agrupamento em genótipos com valor nutritivo equivalente melhora a acurácia na escolha de forragens mais nutritivas e de melhor aproveitamento pelos ruminantes, com impacto no consumo e desempenho, além de contribuir para a redução dos custos com ingredientes suplementares.

Os constituintes químicos PB e FDA e os parâmetros de cinética de degradação ruminal fração solúvel (fração a), taxa de degradação (c) e fração potencialmente degradável (fração b) da MS mostram-se eficientes para conhecimento da divergência nutricional de cascas de vagens de genótipos de feijão-fava, com base em análise multivariada. Considerando-se 
Rev. Bras. Saúde Prod. Anim., Salvador, v.16, n.3, p.571-581 jul./set.., 2015 http://www.rbspa.ufba.br ISSN 15199940

os parâmetros adotados para a formação de agrupamentos pelo método de Tocher, o genótipo de feijão-fava 123 apresenta boa degradação efetiva e taxa de degradação compatível com a de forragens tropicais, além de melhor valor nutritivo e potencial forrageiro que a casca dos demais genótipos de feijão-fava.

\section{AGRADECIMENTOS}

À Fundação cultural e de fomento à pesquisa, ensino e extensão (FADEX), pelo apoio logístico, e ao Banco do nordeste (BNB/ETENE), pelo suporte financeiro à pesquisa.

\section{REFERÊNCIAS}

\section{AGRICULTURAL AND FOOD}

RESEARCH COUNCIL - AFRC.

Energy and protein requirements of ruminants: an advisory manual. Wallingford, UK: Commonwealth Agricultural Bureaux International, 1993. 159p.

\section{ASSOCIATION OF OFFICIAL} ANALYTICAL CHEMISTS - AOAC. Official methods of analysis. $19^{\text {th }} \mathrm{ed}$. Gaithersburg, USA: AOAC International, 2012. 3000p.

AZEVÊDO, J.A.G.; PEREIRA, J.C.; CARNEIRO, P.C.S.; QUEIROZ, A.C.; BARBOSA, M.H.P.; FERNANDES, A.M.; RENNÓ, F.P. Avaliação da divergência nutricional de variedades de cana-de-açúcar (Saccharum spp.).

Revista Brasileira de Zootecnia, v.32, n.6, p.1431-1442, 2003.
AZEVÊDO, J.A.G.; VALADARES

FILHO, S.C.; PINA, D.S.;

VALADARES, R.F.D.; DETMANN, E.;

PAULINO, M.F.; DINIZ; L.L.;

FERNANDES, H.J. Consumo, digestibilidade total, produção de proteína microbiana e balanço de nitrogênio em dietas para ruminantes de subprodutos.

Arquivos Brasileiros de Medicina Veterinária e Zootecnia, v.63, n.1, p.114-123, 2011.

CAMPOS, M.M.; BORGES, A.L.C.C.; LOPES, F.C.F.; PANCOTI, C.G.; REIS e SILVA, R. Degradabilidade in situ da cana-de-açúcar tratada ou não com óxido de cálcio, em novilhas leiteiras Holandês $x$ Gir. Arquivos Brasileiros de Medicina Veterinária e Zootecnia, v.63, n.6, p.1487-1492, 2011.

CARVALHO, G.G.P.; PIRES, A.J.V.; VELOSO, C.M.; SILVA, F.F.; SILVA, R.R. Degradabilidade ruminal do feno de forragens tropicais. Revista Brasileira de Agroecologia, v.12, n.1, p.81-85, 2006.

CAVALCANTI, D.R.; PERIN, F.B.; BENEDETTI, E. Degradabilidade in situ da matéria seca de três forrageiras tropicais nas formas in natura e ensilada.

Arquivo Brasileiro de Medicina Veterinária e Zootecnia, v.64, n.1, p.163-168, 2012.

FERREIRA, A.L.; MAURÍCIO, R.M.; PEREIRA, L.G.R.; AZEVÊDO, J.A.G.; OLIVEIRA, L.S.; PEREIRA, J.M.

Nutritional divergence in genotypes of forage peanut. Revista Brasileira de Zootecnia, v.41, n.4, p.856-863, 2012.

FREITAS, A.W.P.; PEREIRA, J.C.; ROCHA, F.C.; DETMANN, E.; BARBOSA, M.H.P.; RIBEIRO, M.D.; COSTA, M.G. Avaliação da divergência nutricional de genótipos de cana-deaçúcar (Saccharum spp.). Revista Brasileira de Zootecnia, v.35, n.1, p.229-236, 2006. 
Rev. Bras. Saúde Prod. Anim., Salvador, v.16, n.3, p.571-581 jul./set.., 2015 http://www.rbspa.ufba.br ISSN 15199940

MARTINS, A.S.; ZEOULA, L.M.; PRADO, I.N.; MARTINS, E.N.; LOYOLA, V.R. Degradabilidade ruminal in situ da matéria seca e proteína bruta das silagens de milho e sorgo e de alguns alimentos concentrados. Revista Brasileira de Zootecnia, v.28, n.5, p.1109-1117, 1999.

MENEZES, A.P.M.; ASSIS, G.M.L.; MATAVELI, M.; SILVA, H.S.F.; AZEVEDO, J.M.A.; MENDONÇA, M.S. Genetic divergence between genotypes of forage peanut in relation to agronomic and chemical traits. Revista Brasileira de Zootecnia, v.41, n.7, p.1608-1617, 2012.

OLIVEIRA, F.N.; TORRES, S.B.; BENEDITO, C.P. Caracterização botânica e agronômica de acessos de feijão-fava em Mossoró, RN. Revista Caatinga, v.24, n.1, p.143-148, 2011.

OLIVEIRA, E.R.; MONÇÃO, F.P.; GABRIEL, A.M.A.; MOURA, L.V.; LEMPP, B.; SANTOS, M.V.; SOUZA, R. Degradação ruminal da biomassa de fenos de gramíneas do género Cynodon spp. Revista de Ciências Agrárias, v.37, n.2, p.214-220, 2014.

ØRSKOV, E.R.; McDONALD, I. The estimation of protein degradability in the rumen from incubation measurements weighted according to rate of passage. Journal of Agricultural Science, v.92, n.2, p.499503, 1979.

RAO, C.R. Advanced statistical methods in biometric research. New York: John Wiley, 1952. 390p.
RIBEIRO, F.S.C.; SOUZA, V.A.B.; LOPES, A.C.A. Diversidade genética em castanheira-do-gurgueia (Dipteryx lacunifera Ducke) com base em características físicas e químiconutricionais do fruto. Revista Brasileira de Fruticultura, v.34, n.1, p.190-199, 2012.

RODRIGUES, C.S.; NASCIMENTO JÚNIOR, D.; DETMANN, E.; SILVA, S.C.; SOUSA, B.M.L.; SILVEIRA, M.C.T. Grupos funcionais de gramíneas forrageiras tropicais. Revista Brasileira de Zootecnia, v.41, n.6, p.1385-1393, 2012.

SILVA, D.C.; ALVES, A.A.; LACERDA, M.S.B.; MOREIRA FILHO, M.A.; OLVEIRA, M.E.; LAFAYETTI, E.A. Valor nutritivo do capim-andropogon em quatro idades de rebrota em período chuvoso. Revista Brasileira de Saúde e Produção Animal [online], v.15, n.3, p.626-636, 2014.

SIMILI, F.F.; LIMA, M.L.P.; MEDEIROS, M.I.M.; PAZ, C.C.P.; REIS, R.A. Degradabilidade in situ do híbrido de sorgo e do capim-Tanzânia em vacas suplementadas no outono. Boletim de Indústria Animal, v.71, n.2, p.127-134, 2014.

SOUZA, J.R.; BOIÇA JÚNIOR, A.L.; PERECIM, D.; CARGNELUTTI FILHO, A.; COSTA, J.T. Divergência genética de cultivares de cana-de-açúcar quanto à resistência a Diatraea saccharalis. Semina: Ciências Agrárias, v.34, n.6, p.3367-3376, 2013.

UNIVERSIDADE FEDERAL DE VIÇOSA - UFV. SAEG - Sistema de análise estatística e genética. Versão 8.0. Viçosa, MG, 2000. 150p. 
Rev. Bras. Saúde Prod. Anim., Salvador, v.16, n.3, p.571-581 jul./set.., 2015 http://www.rbspa.ufba.br ISSN 15199940

VAN SOEST, P.J.; ROBERTSON, J.B.; LEWIS, B.A. Methods for dietary fiber, neutral detergent fiber, and nonstarch polysaccharides in relation to animal nutrition. Journal of Dairy Science, v.74, n.10, p.3583-3597, 1991.

VASCONCELOS, E.S.; CRUZ, C.D.; BHERING, L.L.; RESENDE JÚNIOR, M.F.R. Método alternativo para análise de agrupamento. Pesquisa

Agropecuária Brasileira, v.42, n.10, p.1421-1428, 2007.

VELÁSQUEZ, P.A.T.; BERCHIELLI, T.T.; REIS, R.A.; RIVERA, A.R.; DIAN, P.H.M.; TEIXEIRA, I.A.M.A. Cinética da fermentação e taxas de degradação de forrageiras tropicais em diferentes idades de corte estimadas pela técnica de produção de gases in vitro. Revista Brasileira de Zootecnia, v.38, n.9, p.1695-1705, 2009.

Data de recebimento: $23 / 07 / 2014$

Data de aprovação: 21/07/2015 